\title{
MODELING AND CONTROL OF A NEW 1/4T SERVO-HYDRAULIC VEHICLE ACTIVE SUSPENSION SYSTEM
}

\author{
Jyh-Chyang Renn \\ Professor, Department of Mechanical Engineering, National Yunlin University of Science and Technology, 640 Douliu, \\ Yunlin,Taiwan., rennjc@yuntech.edu.tw \\ Tsung-Han Wu \\ Graduate Student, Department of Mechanical Engineering, National Yunlin University of Science and Technology, 640 \\ Douliu, Yunlin, Taiwan.
}

Follow this and additional works at: https://jmstt.ntou.edu.tw/journal

Part of the Mechanical Engineering Commons

\section{Recommended Citation}

Renn, Jyh-Chyang and Wu, Tsung-Han (2007) "MODELING AND CONTROL OF A NEW 1/4T SERVO-HYDRAULIC VEHICLE ACTIVE SUSPENSION SYSTEM," Journal of Marine Science and Technology. Vol. 15: Iss. 3, Article 12. DOI: $10.51400 / 2709-6998.2400$

Available at: https://jmstt.ntou.edu.tw/journal/vol15/iss3/12

This Research Article is brought to you for free and open access by Journal of Marine Science and Technology. It has been accepted for inclusion in Journal of Marine Science and Technology by an authorized editor of Journal of Marine Science and Technology. 
MODELING AND CONTROL OF A NEW 1/4T SERVO-HYDRAULIC VEHICLE ACTIVE SUSPENSION SYSTEM

Acknowledgements

The financial support of the National Science Council of ROC under grant number NSC-94-2212-E-224-

014 is greatly appreciated. 


\title{
MODELING AND CONTROL OF A NEW 1/4T SERVO-HYDRAULIC VEHICLE ACTIVE SUSPENSION SYSTEM
}

\author{
Jyh-Chyang Renn* and Tsung-Han $\mathrm{Wu}^{* *}$
}

Key word: servo-hydraulics, active suspension, neural network controller, PID controller.

\begin{abstract}
Nowadays, the active suspension is the key technology for vehicles to achieve both ride comfort and control performance. In this paper, a new 1/4T servo-hydraulic vehicle active suspension system is developed and two control schemes are utilized. The first one is a conventional PID controller obtained from Ziegler-Nichols method and the second one is the neural network controller. Though these two controllers are quite simple and not new, it is still worth mentioning that this paper emphasizes on the engineering aspects including the design of a servo-hydraulic test rig, the implementation technology of the controllers and the subsequent experimental study. In addition, the utilization of MATLAB/Simulink software enables the modeling and dynamic simulation of the control system. From both simulation and experimental results, it is shown that two proposed control schemes can restrain significantly the vibration and acceleration of vehicle body. However, the performance of neural network controller is somewhat better than that obtained from the PID controller.
\end{abstract}

\section{INTRODUCTION}

As shown in Figure 1, the suspension system is classified as a passive, semi-active, and active suspension system, according to its ability to add or extract energy. Among these three systems, the passive suspension is perhaps the most commonly used one and may be found in most vehicles. However, the passive suspension has no means of adding external energy to a system because it contains only passive elements such as a damper and a spring. For the semi-active suspension, though it is possible to continuously vary the rate of energy dissipation using a controllable damper, it provides only moderate performance. By contrast, the

Paper Submitted 08/07/06, Accepted 12/08/06. Author for Correspondence: J.C.Renn.E-mail: rennjc@yuntech.edu.tw.

*Professor, Department of Mechanical Engineering, National Yunlin University of Science and Technology, 640 Douliu, Yunlin, Taiwan.

**Graduate Student, Department of Mechanical Engineering, National Yunlin University of Science and Technology, 640 Douliu, Yunlin, Taiwan. active suspension can supply energy from an external source and generate force to achieve the optimal desired performance. For these reasons, the active suspension is investigated in this study.

Surveying some previous reports, it is found that the active suspension control have been attracting undoubtedly the attention of many engineers and researchers. Typical studies are summarized as follows: Sunwoo et al. [10] used the sky-hook damping model reference adaptive control to improve the ride performance for a quarter car model. Kuo and Li [6] applied the PI and PD fuzzy controllers to the active suspension system, and the optimum parameters of fuzzy controller

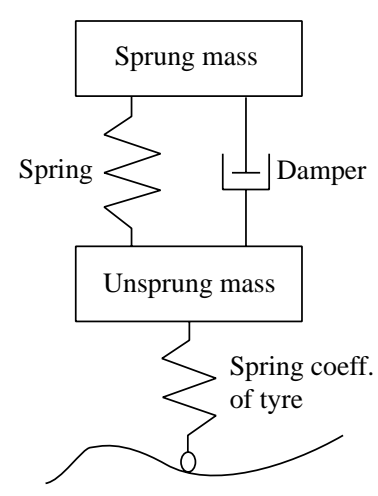

(a) Passive suspension

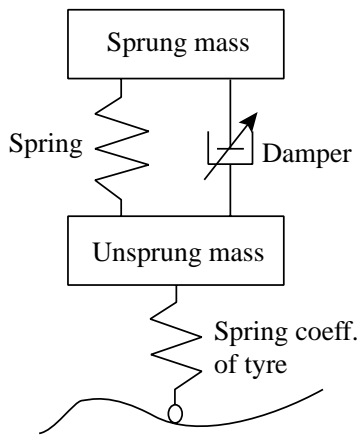

(b) Semi-active suspension

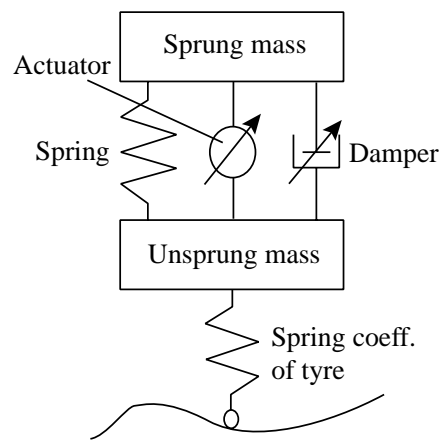

(c) Active suspension
Fig. 1. Classification of vehicle suspension system. 
were obtained by genetic-algorithm (GA). Chantranuwathana and Peng [1] strived to improve the performance of the active suspension system by compensating a dynamic system of hydraulic actuator using a robust controller. Rao and Prahlad [9] proposed a tunable fuzzy logic controller for a quarter-car active suspension model to reduce the vertical acceleration for better ride comfort. Thompson [11] as well as Kashani and Kiriczi [5] applied the optimal control theory to the design of an active vehicle suspension system, but they needed accurate system parameters and road variation information. Lin and Kanellakopoulos [7] employed nonlinear back-stepping design for the control of active suspension systems, which improved the inherent tradeoff between ride quality and suspension level. Kim and Ro [4] used sliding mode control scheme to ensure robustness for a wide range of operating conditions for vehicle active suspension system. Jang and Kim [3] utilized the gain-scheduled control for an active suspension system to improve the ride comfort. Wu and Lee [12] used a neural-network-based fuzzy controller for half-car active suspension systems. However, most of them were based only on computer simulations. In other words, very few experimental results were discussed in these reports.

The actual vehicle has normally 4 wheels. In the laboratory, however, only one wheel is utilized, which is the so-called 1/4T model. That is, only the control of vertical motion is discussed. On the other hand, if the system is well-designed in the vertical motion control, it is generally true that all other motions can also be well controlled. In this paper, the design concepts as well as the modeling, simulation and experimental studies of a newly developed $1 / 4 \mathrm{~T}$ servo-hydraulic active suspension test rig will be discussed. In addition, two controller schemes will be utilized. The first one is the conventional PID controller and the second one is the neural network controller. In the following, the structure of the vehicle active suspension system will firstly be outlined.

\section{ACTIVE SUSPENSION SYSTEM}

The introduction of active suspension system is expected to improve efficiently the control performance and the ride comfort for passengers in a vehicle. Generally speaking, a high-quality active suspension system can separate the vehicle chassis from the vibration arising from road surface. It further ensures the contact between the wheels and road surface for a better ride comfort and safety. A $1 / 4 \mathrm{~T}$ vehicle model using a socalled sky-hook damper is shown in Figure 2. The skyhook damper refers to a damper attached between the top and ceiling of vehicle. This damper is found to have excellent suppression effect against the vibration of vehicle body [10]. The bsky denotes the damping coefficient of the sky-hook damper.

Since it is difficult to practically implement the sky-hook suspension system, this study adopts a feedback control structure instead of the sky-hook suspension and designs a servo-hydraulic active suspension system as shown in Figure 3. The basic principle is described as follows: a hydraulic actuator is mounted between the vehicle and wheels, such that the controllable output force of the hydraulic cylinder is used to replace the virtual damping force provided by the skyhook damper. This helps to realize the same damping effect of sky-hook damper. The parameter $F_{a}$ denotes the output force provided by the hydraulic cylinder.

The dynamic equations for the active suspension system are

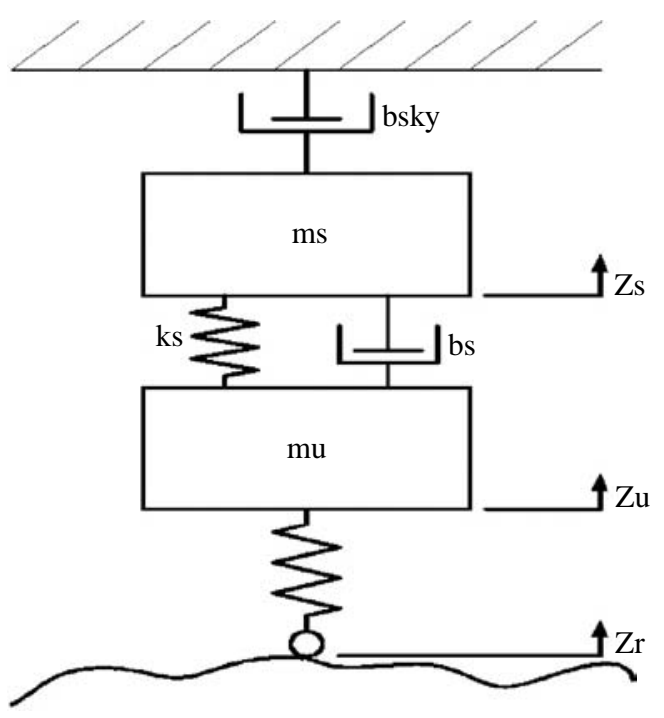

Fig. 2. Sky-Hook suspension system.

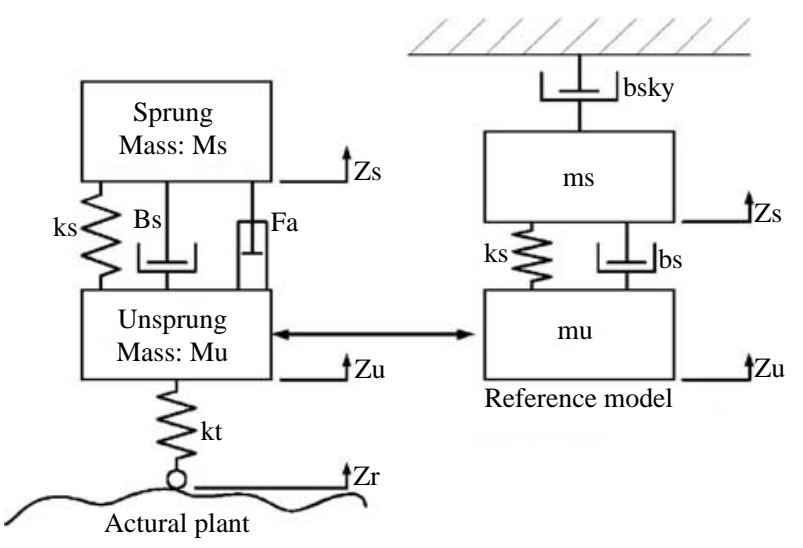

Fig. 3. Active suspension system of sky-hook reference model. 


$$
\begin{aligned}
& m_{s} \ddot{z}_{s}=k_{s}\left(z_{u}-z_{s}\right)+b_{s}\left(\dot{z}_{u}-\dot{z}_{s}\right)+F_{a} \\
& m_{u} \ddot{z}_{u}=-k_{s}\left(z_{u}-z_{s}\right)-b_{s}\left(\dot{z}_{u}-\dot{z}_{s}\right)+k_{t}\left(z_{r}-z_{u}\right)-F_{a}
\end{aligned}
$$

Where,

$m_{s}$ : sprung mass $(303 \mathrm{~kg})$,

$m_{u}$ : unsprung mass $(65 \mathrm{~kg})$,

$k_{s}$ : spring constant $(16812 \mathrm{~N} / \mathrm{m})$,

$k_{t}$ : spring constant of tyre $(190000 \mathrm{~N} / \mathrm{m})$,

$b_{s}$ : damper coefficient $(10000 \mathrm{Ns} / \mathrm{m})$

$Z_{s}$ : displacement of vehicle chassis relative to plain ground,

$Z_{u}$ : displacement of wheel relative to plain ground,

$Z_{r}$ : uneven road surface relative to plain ground,

$F_{a}$ : output force provided by the servo-hydraulic cylinder.

As shown in Figure 4, the servo-hydraulic actuator consists of a servo valve (or proportional valve) and a hydraulic cylinder. The output actuating force $F_{a}$ is calculated by

$$
F_{a}=A P_{L}
$$

From the continuity Eq. [8], Eq. (4) can be derived.

$$
\frac{V_{t}}{4 \beta_{e}} \dot{P}_{L}=Q_{L}-C_{t} P_{L}-A\left(\dot{z}_{s}-\dot{z}_{u}\right)
$$

From the Bernoulli's Eq. [8], assuming that the rod diameter is negligible, we have

$$
Q_{L}=C_{d} w x_{v} \sqrt{\frac{1}{\rho}\left(P_{S}-P_{L}\right)} .
$$

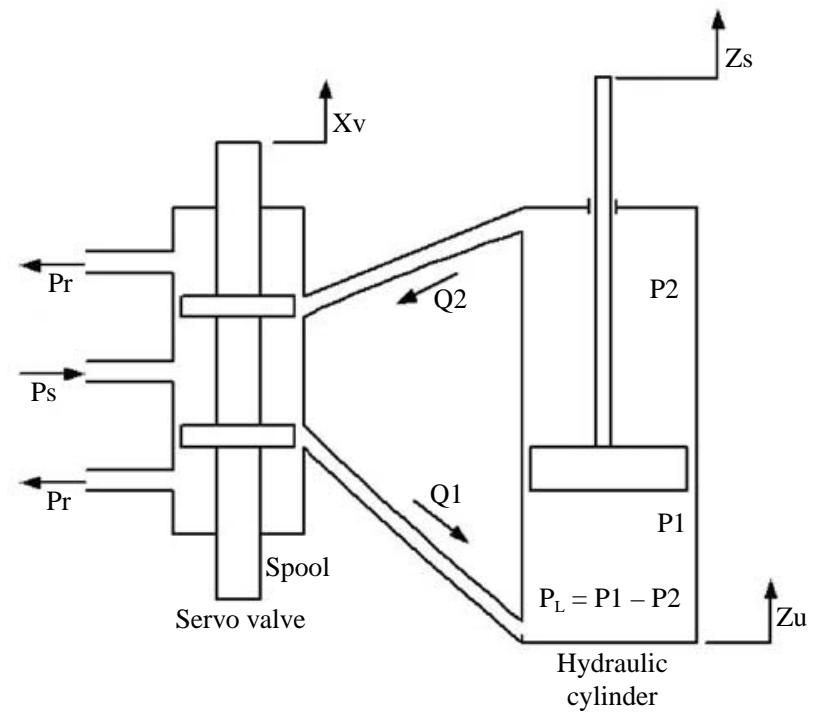

Fig. 4. The servo-hydraulic actuator.
Where,

$A$ : effective cross-sectional area of hydraulic cylinder $\left(903 \mathrm{~mm}^{2}\right)$,

$P_{L}$ : load pressure,

$V_{t}$ : effective volume of hydraulic cylinder,

$\beta_{e}$ : bulk modulus of oil,

$C_{t}$ : leakage coefficient of hydraulic cylinder,

$Q_{L}$ : load flow,

$C_{d}$ : discharge coefficient,

$w$ : area gradient of servo valve,

$x_{v}$ : spool displacement of servo valve,

$\rho$ : oil density,

$P_{s}$ : supply pressure (110 bar).

In addition, the spool displacement of servo valve, $x_{v}$, is controlled by an input current, $u$. The corresponding dynamic relation can be simplified as a first-order differential equation.

$$
\dot{x}_{v}=\frac{1}{\tau}\left(-x_{v}+k_{a} u\right) \text {. }
$$

From Eqs. (1) to (6), if the state variables are selected as: $x_{1}=z_{s}-z_{u}, x_{2}=\dot{z}_{s}, x_{3}=z_{u}-z_{r}, x_{4}=\dot{z}_{u}, x_{5}$ $=P_{L}$ and $x_{6}=x_{v}$, the state equations for the active suspension system may be written as

$$
\begin{aligned}
& \dot{x}_{1}=x_{2}, \\
& \dot{x}_{2}=\frac{1}{m_{s}}\left[-k_{s}\left(x_{1}-x_{3}\right)-b_{s}\left(x_{2}-x_{4}\right)-A x_{5}\right], \\
& \dot{x}_{3}=x_{4}, \\
& \dot{x}_{4}=\frac{1}{m_{u}}\left[k_{s}\left(x_{1}-x_{3}\right)+b_{s}\left(x_{2}-x_{4}\right)+k_{t}\left(Z_{r}-x_{3}\right)-A x_{5}\right], \\
& \dot{x}_{5}=-\beta x_{5}-\alpha A\left(x_{2}-x_{4}\right)+\gamma x_{6} \sqrt{P_{S}-\operatorname{sgn}\left(x_{6}\right) x_{5}}, \\
& \dot{x}_{6}=\frac{1}{\tau}\left(-x_{6}+k_{a} u\right), \\
& y=A x_{5} .
\end{aligned}
$$

Where $\alpha=\frac{4 \beta_{e}}{V_{t}}, \beta=\alpha C_{t}, \gamma=\alpha C_{d} w \sqrt{\frac{1}{\rho}}$.

\section{PID AND NEURAL NETWORK CONTROL THEORY}

In this study, the first utilized control scheme is the PID controller, in which the optimal gains are determined by the criterion proposed by Ziegler and Nichols [13]. The discrete-time PID-controller can be formulated as 
$u(k)=u(k-1)+\Delta u(k)$

$$
\begin{aligned}
\Delta u(k) & =K_{P}[e(k)-e(k-1)]+K_{I} e(k) \\
& +K_{D}[e(k)-2 e(k-1)+e(k-2)]
\end{aligned}
$$

where $u(k)$ : actuating signal,

$\Delta u(k)$ : actuating signal change,

$e(k)$ : error signal,

$K_{P}$ : gain of the proportional controller,

$K_{I}$ : gain of the integral controller,

$K_{D}$ : gain of the derivative controller.

The second control scheme proposed in this paper is the neural network controller. On the one hand, the neural network possesses the structure of Multilayer Perception (MLP) and utilizes the algorithm of Error Back Propagation (EBP). The combination of MLP and EBP is called the BP Neural Network or simply BPN, which is the most frequently used neural network controller for engineering applications. On the other hand, the main framework of the BPN consists of the multilayer feedforward structure as well as the supervised learning architecture. It features a higher level of nonlinear mapping and rapid learning. Therefore, the BPN can be used to replace the conventional nonlinear equations and the corresponding complex calculations [2].

Figure 5 shows the schematic BPN controller proposed in this paper. It is observable that the controller consists of three layers. They are input, hidden and output layer respectively. This structure is called the multilayer feedforward network, which can be used to solve complex nonlinear model. The input and output layer represents the input and output value respectively. The number of Neuros in input or output layer is determined simply according to the number of utilized input or output variables in the model. In addition, the necessary number of Neuros in hidden layer depends chiefly on the complexity of the control system. Generally speaking, more Neuros result in better learning ability. By contrast, the learning efficiency decreases because more time is required for computation. Therefore, trial-and-error method is generally used to determine the optimal number of Neuros in hidden layer. Besides, the number of hidden layer can be increased from one layer to several layers depending also upon the complexity of the system. In this paper, however, only one hidden layer with three Neuros is employed. In addition, both the input and output layer consists of a single Neuro respectively. The Neuros in various layers are interlinked by different weight. The input pattern is directly transferred to the hidden layer through the input layer. After some calculations including weighting, summation and activation, a set of output values in hidden layer is obtained. Similarly, the actual output values in output layer can also be derived. Figure 6 shows the simplified control block diagram of the active suspension system using neural network controller. The desired input, $Z_{s d}$, is set to be zero in order to maintain zero displacement of vehicle body (i. e. sprung mass) regardless of the disturbance, $Z_{r}$, caused by uneven road profile. Obviously, the only one input value to the input layer is the minus vehicle body displacement, $-Z_{s}$. Some details of the BPN will be depicted in the following paragraphs.

The most essential element of neural network is the neural cell, which is called Neuro in this study. Figure 7 illustrates the model of a Neuro, in which the symbol $f(\cdot)$ denotes the activation function. In this paper, the Sigmoid activation function is utilized because it is continuously differentiable. The mathemati-

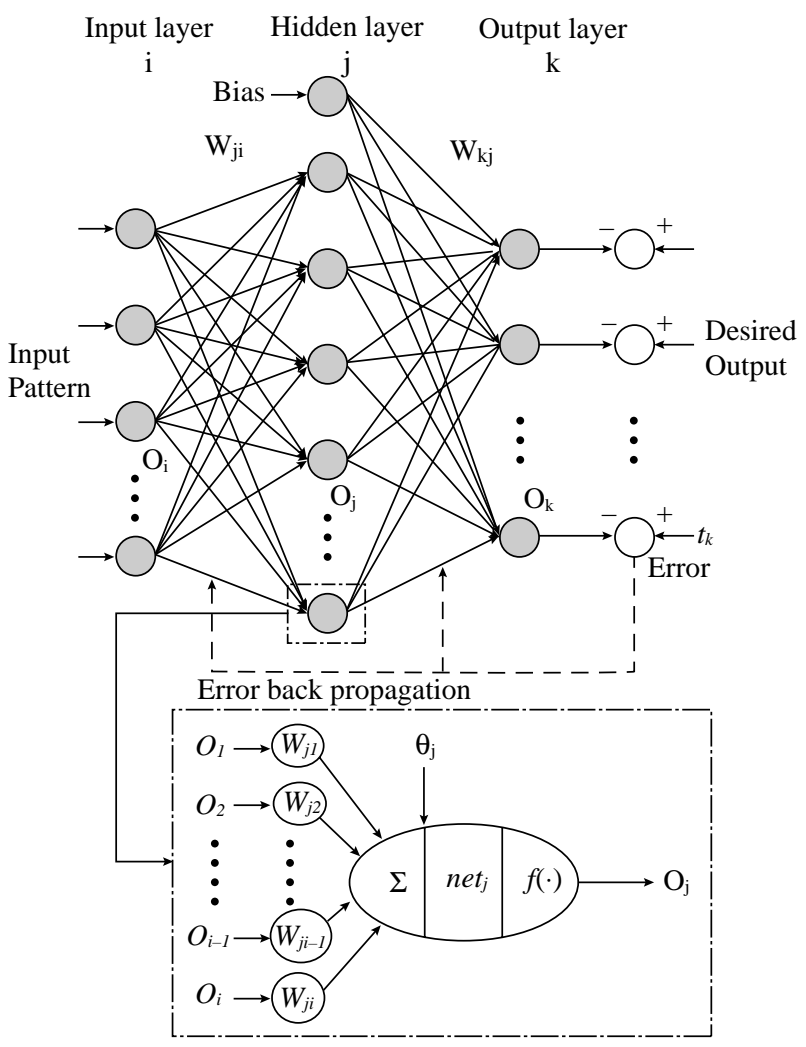

Fig. 5. BP Neural Network controller.

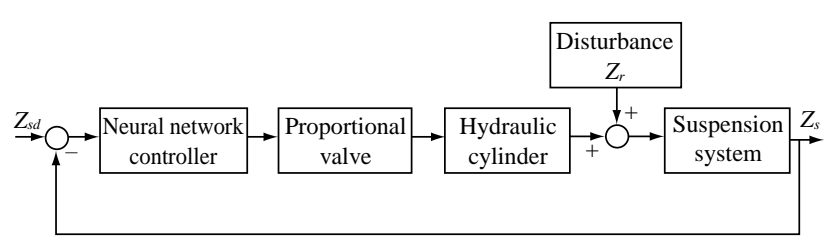

Fig. 6. Simplified block diagram of the active suspension system using neural network controller. 


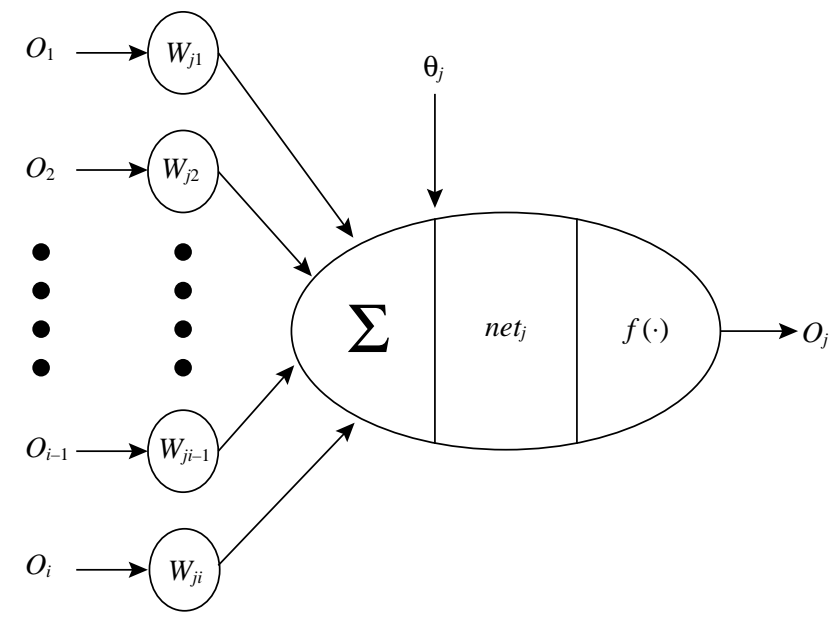

Fig. 7. The model of a Neuro.

cal equations for the Neuro are [2]

$$
n e t_{j}=\Sigma\left(W_{j i} \cdot O_{i}\right)+\theta_{j}
$$

and

$$
O_{j}=\frac{1}{1+\exp \left(-n e t_{j}\right)} .
$$

Where,

$W_{j i}$ : weight from Neuro $i$ in input layer to Neuro $j$ in hidden layer,

$\theta_{j}$ : bias or threshold at Neuro $j$,

$O_{i}$ : input value from Neuro $i$ in input layer,

$O_{j}$ : output value of Neuro $j$ in hidden layer.

Figure 8 shows the network of EBP, which is proved to be the most effective supervised learning architecture. The basic principle is the utilization of Gradient Steepest Descent Method (GSDM) [2]. First, an error function is defined using GSDM. Thus, it is possible to adjust the weight and/or bias during the learning process if this error function is minimized. The error function, $E$, is defined as

$$
E=\frac{1}{2} \sum\left(t_{k}-O_{k}\right)^{2}
$$

Where,

$t_{k}$ : desired output value of Neuro $k$ in output layer,

$O_{k}$ : actual network output value of Neuro $k$ in output layer.

The output value, $O_{k}$, in output layer can be obtained through

$$
O_{k}=f_{k}\left(n e t_{k}\right)=\frac{1}{1+\exp \left(-n e t_{k}\right)},
$$

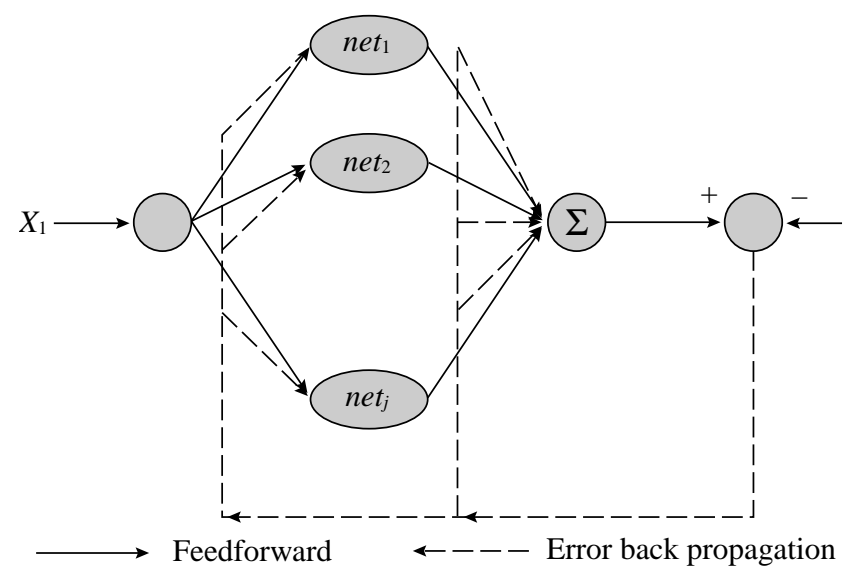

Fig. 8. The network of EBP.

$$
n e t_{k}=\Sigma\left(W_{k j} \cdot O_{j}\right)+\theta_{k}
$$

Where,

$W_{k j}$ : weight from Neuro $j$ in hidden layer to Neuro $k$ in output layer,

$O_{j}$ : output value of Neuro $j$ in hidden layer,

$\theta_{k}$ : bias or threshold at Neuro $k$.

To minimize the error function, $E$, the following equation is utilized.

$$
\Delta W=-\eta \frac{\partial E}{\partial W}
$$

Where $\Delta W$ is the weight change and $\eta$ denotes the learning rate, which is the proportional gain between the weight change and the partial differential error function. Thus, the weight can be adjusted or updated by

$$
W(k)=W(k-1)+\Delta W .
$$

This iteration process stops if the error function, $E$, converges within a preset bound.

\section{EXPERIMENTAL TEST RIG}

Figure 9 shows the schematic layout of the test rig. The functional block diagram is shown in Figure 10. There are two closed-loop hydraulic control units installed in the test rig. One is the road profile simulator unit used to simulate different road excitation. The other is the closed-loop controlled servo-hydraulic active suspension system to attenuate the road disturbance. The road actuator is basically a single-acting hydraulic cylinder with a maximal stroke of $150 \mathrm{~mm}$. To precisely 


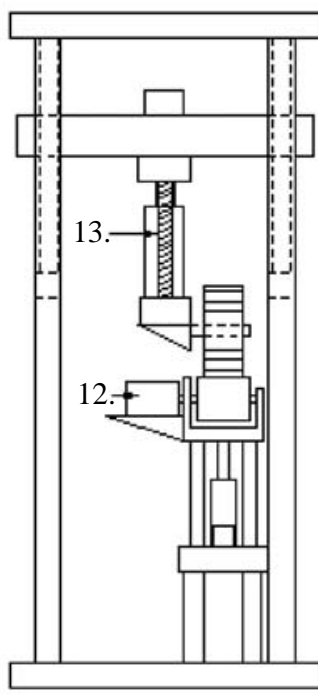

1. Accelerometer

2. Sprung mass

3. Optical scale

4. Potentiometer (1)

5. Hyd. cylinder (1)

6. Tyre

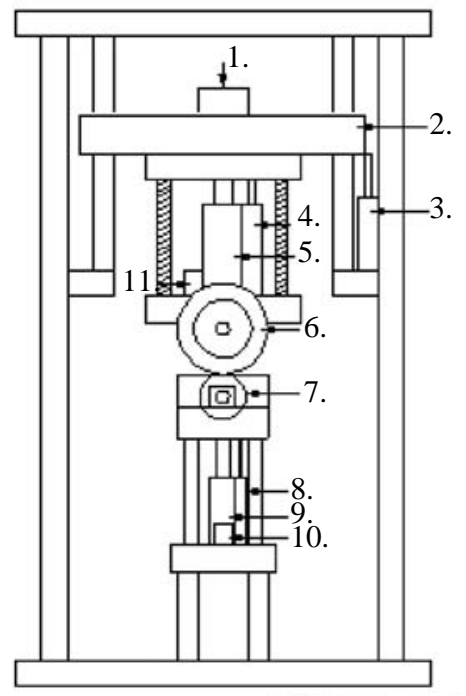

7. Roller

8. Potentiometer(2)

9. Hyd. cylinder(2)

10. Prop. valve(1)

11. Prop. valve(2)

12. Hyd. motor

13. Spring

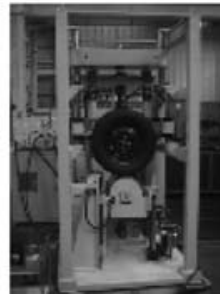

Fig. 9. 1/4T test rig for active suspension system. control the displacement of the road actuator, a linear potentiometer and a high-speed proportional valve (Parker-D1FH series) are employed. The system pressure is fixed at 70 bar. Thus, different road excitations can be generated in the laboratory.

As for the active suspension system, the controllable output force of the single-acting hydraulic cylinder is used to maintain the zero displacement of the sprung mass. To achieve this, a linear potentiometer as well as a high-speed proportional valve (Parker-D1FH series) is also utilized. The suspension hydraulic cylinder (component No. 5 in Figure 9) has an effective cross-sectional area of $903 \mathrm{~mm}^{2}$ and a maximal stroke of $150 \mathrm{~mm}$. For evaluating the ride comfort, an accelerometer is installed on the sprung mass to measure the vertical acceleration. The system pressure is fixed at 110 bar. Finally, the control of this test rig as well as the acquisition and processing of measured data are all integrated in a PC-based control unit with a multifunctional peripheral interface card.

\section{SIMULATION AND EXPERIMENTAL RESULTS}

For vehicles, the most critical road affecting the ride comfort is the random and uneven road profile. In

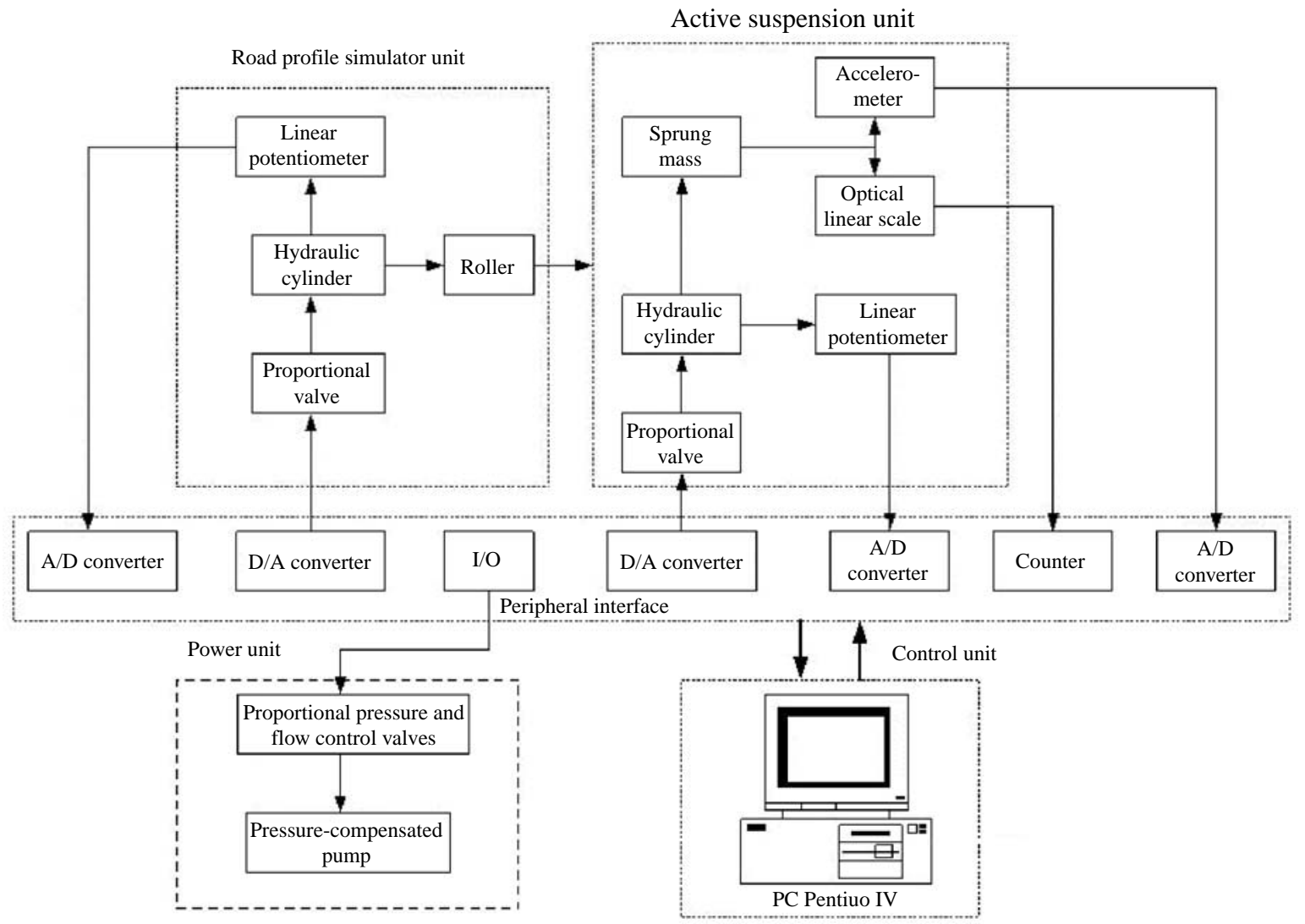

Fig. 10. Functional block diagram of the test rig. 
the laboratory, however, simplification of the real road profile is necessary. The road profile test input chosen in this study is a flat road surface with a sinusoidal concave bump followed by a sinusoidal convex bump, which is generated by the closed-loop controlled road profile simulator (component No. 9 in Figure 9). Figure 11 shows the simulation results using the state Eqs. (7) as well as the MATLAB/Simulink software. The experimental results are shown in Figure 12. The displacement signal is measured by the optical linear scale (component No. 3 in Figure 9) attached to the chassis (i. e. sprung mass) of the vehicle. It is observed that the amplitude of oscillation of the vehicle body after passing the bumps with active suspension using neural network controller is somewhat smaller than that using

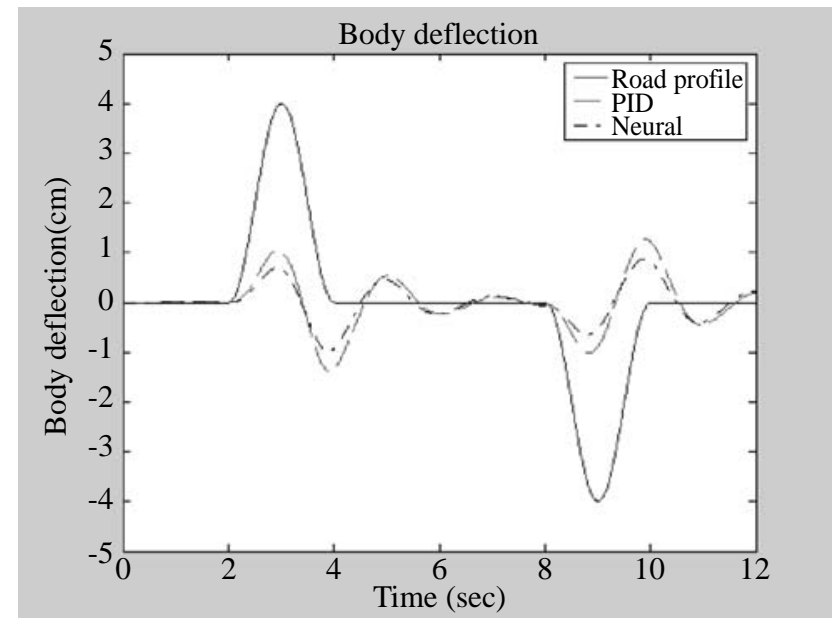

Fig. 11. Simulation results showing the displacement of vehicle body subjected to $4 \mathrm{~cm}$ convex and concave bumps.

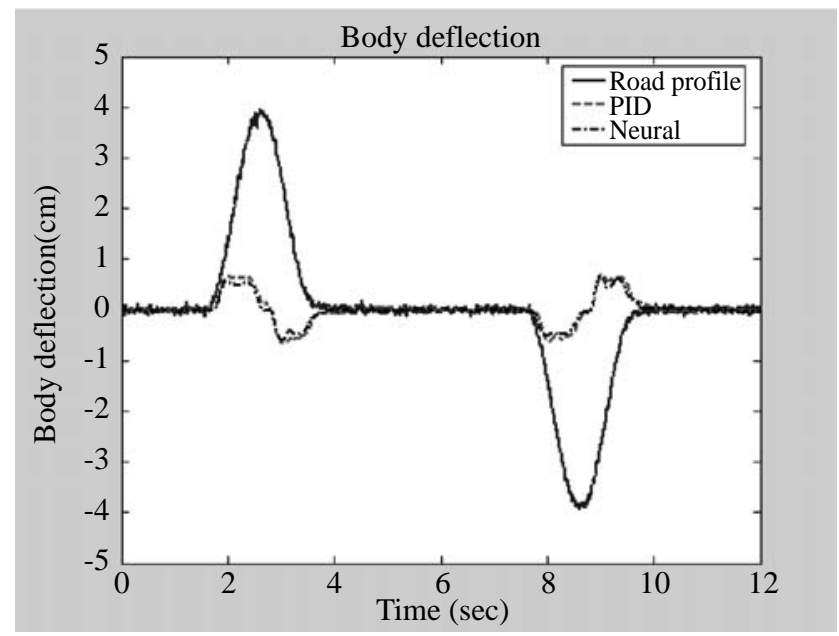

Fig. 12. Experimental results showing the displacement of vehicle body subjected to $4 \mathrm{~cm}$ convex and concave bumps. the PID controller. That is, the control performance is improved.

On the other hand, Figure 13 and Figure 14 show the corresponding simulation and measured acceleration signals. In addition to two main acceleration signals of vehicle body obtained from PID and neural network controller respectively, the acceleration of the road profile generated by the servo-hydraulic road simulator is also shown in the figures for references. Although the measured acceleration signals are oscillatory, the acceleration of the vehicle body using neural network controller is smaller. In other words, the ride comfort is improved. Table 1 shows the quantitative comparisons between the performances using PID and neural network controller. From either the maximal

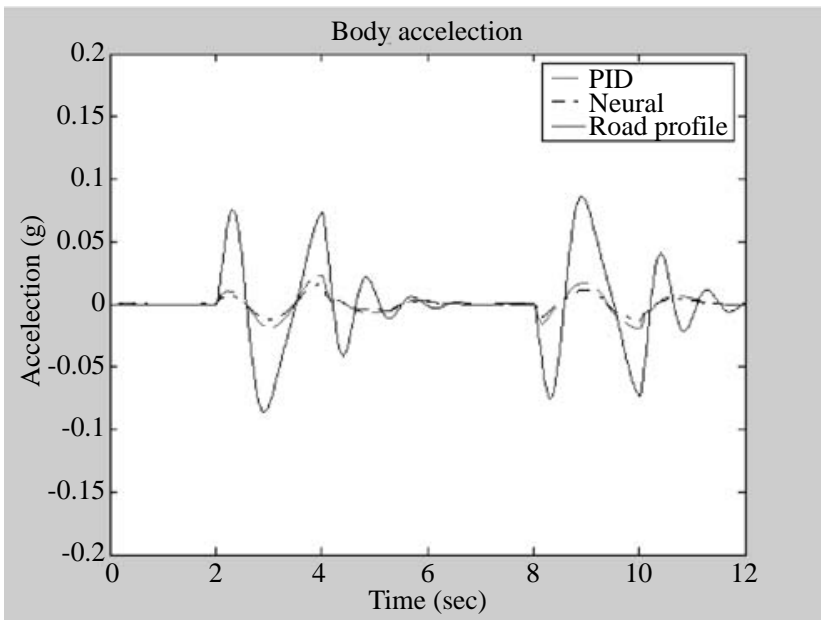

Fig. 13. Simulation results showing the acceleration of vehicle body subjected to $4 \mathrm{~cm}$ convex and concave bumps.

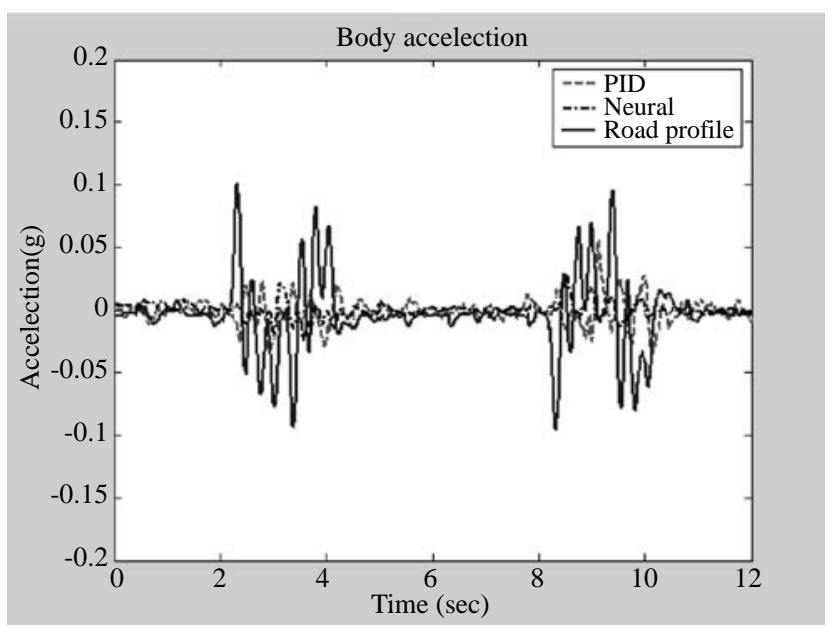

Fig. 14. Experimental results showing the acceleration of vehicle body subjected to $4 \mathrm{~cm}$ convex and concave bumps. 
Table 1. Quantitative comparisons between PID and neural network controller

\begin{tabular}{cccc}
\hline Simulation & $\begin{array}{c}\text { Maximal } \\
\text { absolute } \\
\text { acceleration } \\
(\mathrm{g})\end{array}$ & $\begin{array}{c}\text { Maximal body } \\
\text { absolute } \\
\text { displacement } \\
(\mathrm{cm})\end{array}$ \\
\hline \multirow{2}{*}{ PID } & 0.03 & 1 \\
& Experiment & 0.04 & 0.8 \\
\hline Neural & Simulation & 0.02 & 0.7 \\
Network & Experiment & 0.03 & 0.7 \\
\hline
\end{tabular}

absolute value of body acceleration or displacement, it can be concluded that the proposed neural network controller is somewhat better than the conventional PID controller.

\section{CONCLUSION}

In this paper, a test rig of servo-hydraulic active suspension system for vehicles is successfully developed. From both simulation and experimental results, it is proved that both two control schemes can restrain the vibration and acceleration of vehicle body significantly. However, three remarks are given as follows.

1. For the real application in vehicles, the proposed active suspension structure faces inevitably some challenges including the cost, the required space in vehicle and the difficulty to acquire the displacement of wheel, $Z_{u}$. In the developed test rig, the displacement of wheel was easily measures by the installed potentiometer (component No. 8 in Figure 9). In a real vehicle, however, the install of such a potentiometer is practically impossible. One possible solution is the utilization of an accelerometer to acquire first the acceleration of the wheel. And then, the numerical integration may be used to calculate the required position signal.

2. The developed PC-based controller can actually not be implemented in a real vehicle application because of the bulky dimension. One feasible solution is the introduction of DSP control system.

3. Since the servo-hydraulic system is highly nonlinear and time-varying, it is reasonable to have the result that the proposed neural network controller is able to suppress the vibration amplitude and subsequent acceleration of the vehicle body in a more efficient manner than the conventional PID controller. For the real application, however, PID controller is still the best choice because of its simplicity and easy implementation.

\section{ACKNOWLEDGEMENT}

The financial support of the National Science Council of ROC under grant number NSC-94-2212-E-224014 is greatly appreciated.

\section{REFERENCES}

1. Chantranuwathana, S. and Peng, H., "Adaptive Robust Control for Active Suspensions," Proceeding of the 1999 American Control Conference, pp. 1702-1706 (1999).

2. Fukuda, T. and Shibata, T., "Theory and Application of Neural Networks for Industrial Control System," IEEE Transaction on Industrial Electronics, pp. 472-489 (1992).

3. Jang, Y.J. and Kim, S.W., "Gain-Scheduled Control for an Active Suspension System with an Asymmetric Hydraulic Actuator," IEICE Transactions Fundamentals, Vol. E85-A, No. 4, pp. 903-908 (2002).

4. Kim, C. and Ro, P.I., "A Sliding Mode Controller for Vehicle Active Suspension Systems with Nonlinearities," Proceedings of the Institution of Mechanical Engineers, Vol. 212, pp. 79-92 (1998).

5. Kiriczi, S.B. and Kashani, R., "Robust Stability Analysis of LQG-Controlled Active Suspension with Model Uncertainty Using Structure Singular Value, $\mu$, Method," Vehicle System Dynamics, Vol. 21, pp. 361-384 (1992).

6. Kuo, Y.P., Hseng, T., and Li, S., "GA-Based Fuzzy PI/ PD Controller for Automotive Active Suspension System," IEEE Transactions on Industrial Electronics, Vol. 46, No. 6, pp. 1051-1056 (1999).

7. Lin, J.S. and Kanellakopoulos, I., "Nonlinear Design of Active Suspensions," IEEE Control System, June, pp. 45-59 (1997).

8. Merritt, H.E., Hydraulic Control system, John Wiley \& Sons, Inc., New York (1967).

9. Rao, M.V.C and Prahlad, V., "A Tunable Fuzzy Logic Controller for Vehicle-active Suspension System," Fuzzy Sets and Systems, Vol. 85, pp. 11-21 (1997).

10. Sunwoo, M., Cheok, K.C., and Huang, N.J., "Model Reference Adaptive Control for Vehicle Active Suspension Systems," IEEE Transactions on Industrial Electronics, Vol. 38, No. 3, pp. 217-222 (1991).

11. Thompson, A.G., "Optimal and Suboptimal Linear Active Suspensions for Road Vehicles," Vehicle System Dynamics, Vol. 13, pp. 61-72 (1984).

12. Wu, S.J., Wu, C.T., and Lee, T.T., "Neural-NetworkBased Optimal Fuzzy Control Design for Half-Car Active Suspension Systems," Proceedings of the Intelligent Vehicle Symposium, Las Vegas, CA (2005).

13. Ziegler, J.G. and Nichols, N.B., "Optimum Settings for Automatic Controllers," Transactions of ASME, Vol. 64, pp. 759-768 (1942). 